\title{
Procedure to Use PZT Sensors in Vibration and Load Measurements
}

\author{
C. N. Sathyanarayana, ${ }^{1,2}$ S. Raja, ${ }^{1}$ and H. M. Ragavendra ${ }^{1}$ \\ ${ }^{1}$ Structural Technologies Division, Dynamics and Adaptive Structures Group, CSIR-National Aerospace Laboratories, \\ Bangalore, Karnataka 560 017, India \\ ${ }^{2}$ VTU, Belgaum, Karnataka 590 018, India
}

Correspondence should be addressed to S. Raja; raja@nal.res.in

Received 21 March 2013; Revised 16 September 2013; Accepted 19 September 2013

Academic Editor: Chris Bowen

Copyright (c) 2013 C. N. Sathyanarayana et al. This is an open access article distributed under the Creative Commons Attribution License, which permits unrestricted use, distribution, and reproduction in any medium, provided the original work is properly cited.

In situ correlation procedure is developed for electromechanically coupled PZT sensors to output the structural responses in standard engineering format, namely, displacement, strain, acceleration, and so forth. In order to implement this idea, we have used the standard sensing devices such as laser displacement sensor, strain gauge, and accelerometer. Aluminum beams and composite plate are employed in the experiments as specimens. The experimental results have shown that the structural reactions at critical locations can be monitored by a dynamically correlated PZT patch sensor, besides measuring the intensity of load in terms of acceleration. Furthermore, the influence of damage on sensor correlation has been evaluated. It is seen that the presence of damage has significantly modified the interpreted engineering parameters from the PZT patch and if they are appropriately correlated with respect to healthy structure, then the occurrence of damage related information will be ascertained. The developed sensor correlation concept therefore may be useful in load monitoring, health monitoring, and structural control applications.

\section{Introduction}

Piezoelectric materials are a class of smart materials, which can be used as sensors and actuators to build adaptive and health monitoring aerospace structures. Introduction of these multifunctional materials into composites offers a great potential for stiffness tailoring, static shape correction, health monitoring, and vibration control applications [1-6]. Future unmanned aerospace vehicles demand high performance structural systems with self-thinking and adaptive capabilities, where piezoelectric composite materials may be considered as a solution to build adaptive structural concepts [79]. A structural system can be made diagnosable, when it is able to communicate its response with respect to various disturbances. In this regard, PZT material in thin film form provides the distributed sensing opportunity for the structural system to read its spatial information. However the data read from the sensors must be interpreted or examined with a proven health monitoring algorithm or procedure for knowing the vital information such as occurrence of damage, intensity of damage, location of damage, and loading intensity. The sensory information may be static or dynamic (vibration) in real time; therefore the electromechanically coupled (PZT) sensor is found suitable for a frequency dependent response monitoring application.

Structural health monitoring concepts, involving piezoelectric sensors, have got considerable attention in aerospace/ other engineering applications. Aerodynamic flow over an aircraft surface may cause its structural modes to get excited at resonant or off-resonant conditions depending upon its maneuvering. Also thin airframe structures may vibrate in single or multiple modes for a long time due to low structural damping. Therefore, vibration responses may be monitored to obtain the health states of the structures and the loads. Thus observation of dynamics of elastic modes becomes important not only for damage prediction but also for residual life estimation $[10,11]$. Aerospace structures usually undergo turbulent aerodynamic environments during their operational life span, which make them have fatigue and to be susceptible to stability and strength related problems. Therefore, inspection and maintenance of aircraft subsystems are important aspects for commercial airlines/air forces. Aircraft structure is being one of the major subsystems that needs monitoring of its health to provide the necessary reduction in maintenance 
cost. PZT thin films and fibre optic sensors play a major role in devising SHM schemes for building high performance structures [12-19].

Park et al. [20] have evaluated the performance of different sensors for damage detection in glass fibre/epoxy composites through acoustic emission measurements. Bonfiglioli et al. [21] have investigated the measurement errors of electric strain gauges (ESG) on FRP and its length is observed to be a critical factor, when the surface of the FRP material is very rough. Other notable studies on structural health monitoring using PZT are reported [22-28]. Recently Diamanti and Soutis [29] have presented a review on currently used inspection methods and cited some examples, where Lamb wave based scanning techniques are used to identify internal damage in multilayered composite structures.

In general, the SHM techniques integrate various elements, namely, sensors, algorithms, data acquisition system, and processor. Qualification and quantification of any sensor data depend upon its calibration. Any fault in sensor data may wrongly be interpreted for damage assessment analysis or load monitoring, if the sensor signal is not properly quantified. Therefore in situ correlation is required for PZT sensor in order to get a reliable structural data and also for monitoring the health of sensors periodically, mounted on the structure. The sensitivity factor of accelerometer and gage factor of strain gauge are normally provided by the manufacturer such that these factors can be used in the vibration response analysis. In case of PZT sensor, such a sensitivity factor is not available. Therefore it is essential to quantify the PZT sensor to obtain a correlation factor, so that its output signal can be interpreted in standard engineering units. In fact calibration procedure is required for multifunctional composite sensing structure to output the responses at distributed locations, which can be quantifiable for load monitoring application. Therefore, in the present work, procedures are developed for correlating the PZT sensor output, which is surface bonded on a host structure with the help of strain gauge, laser sensor, and accelerometer.

\section{Vibration and Load Monitoring}

The PZT sensor basically will output charge and with the help of a proper conditioner, we can obtain this charge into voltage form. An attempt has been made to interpret this charge or voltage data in different engineering format through correlation procedures, namely, acceleration, strain, and displacement, without differentiating or integrating the signal either digitally or electronically. Therefore, the sensor data may be employed in a structural damage assessment analysis and the interpreted data can also be used for load monitoring applications in unmanned air vehicles (UAV).

In this approach, the following procedures are involved.

(i) Identify the critical vibration modes (flutter, gust/ buffet, and so forth) from the pool of elastic modes.

The dynamic stress amplitude may bring problems such as gust, buffet; damping will pose stability related issue for the structure, for example, flutter of wing or tail of airplane. Therefore, we can monitor these modes not only from the ageing structure point of view but also for load intensity. After identifying the critical modes, the modal parameters such as amplitude, damping, and frequency may be monitored to examine the occurrence of damage, if any, using suitable algorithm. In general, if the damage is not large enough, frequency and amplitude will not display much variation and damping being a nonlinear parameter can certainly cause problem in diagnosis. Therefore, it is desirable to monitor the dynamic strains.

(ii) For every critical mode, the most influential strain, that is, either normal strains $\left(\varepsilon_{x x}, \varepsilon_{y y}\right)$ or shear strain $\left(\varepsilon_{x y}\right)$, can be identified for monitoring purpose.

Therefore directional PZT sensor can be correlated to observe these critical strains. For this purpose, PZT thin film can be geometrically shaped into a rosette form.

(iii) The PZT thin patch may be correlated to output engineering parameters (acceleration, displacement), so that the measured strains can be interpreted for load monitoring applications under different maneuvers, which will be very much beneficial for a fully autonomous UAV flight.

(iv) Vibration parameters such as frequency, amplitude, and damping can be obtained from the measured dynamic strain using standard modal analysis tools.

2.1. Correlation Procedure for PZT Patch. In this section, procedures are presented on how to correlate a PZT patch output (capacitive sensor), which cannot be quantified with respect to standard sensors like accelerometer, strain gage, and laser sensor under dynamic loading.

The three steps procedures are outlined here.

Step 1. Initially the correlation factor $(\mathrm{g} / \mathrm{pC})$ is assumed to be unity and the response from the PZT patch is collected on a charge mode. Simultaneously, the acceleration is also measured $(\mathrm{mV} / \mathrm{g})$ from a reference accelerometer with known sensitivity. These measurements are made on a beam, which is vibrated to a known input force (" $g$ ").

Step 2. From the acquired charge quantity $q$, we get $g=q \mathrm{pC}$; therefore now the actual correlation factor is computed for the PZT sensor in terms of " $\mathrm{pC} / \mathrm{g}$ ", since the input disturbance is known. Alternatively, equivalent sensor voltage may also be measured from PZT patch to interpret its output in " $\mathrm{mV} / \mathrm{g}$ " directly, using a charge conditioner.

Step 3. Now using the estimated correlation factor $(\mathrm{pC} / \mathrm{g})$, once again the charge measurement is made and verified with a reference acceleration signal $(\mathrm{mV} / \mathrm{g})$.

Now the PZT output with respect to accelerometer can be interpreted for charge to acceleration $(\mathrm{pC} / \mathrm{g})$. The above procedure can be adopted for the PZT sensors with respect to any standard measurement devices like surface bonded strain gage or noncontact laser velocity and displacement 


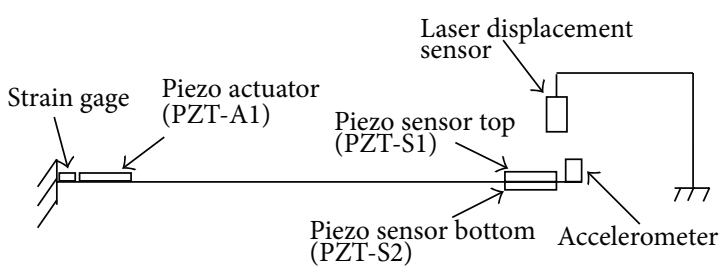

FIGURE 1: Instrumented beam for in situ PZT sensor correlation.

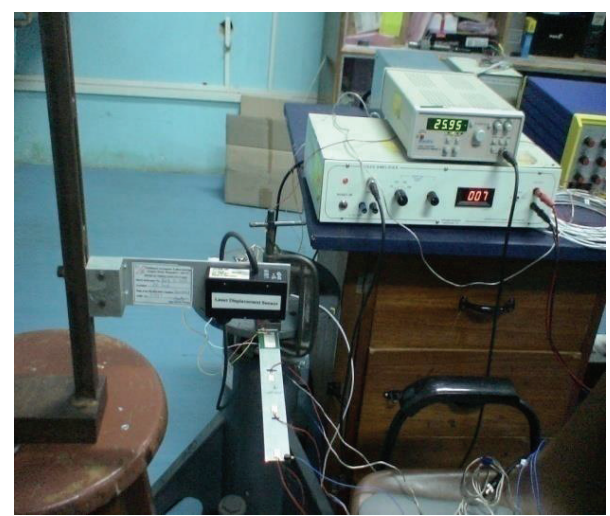

FIgURE 2: Experimental setup for PZT sensor correlation with standard sensors.

sensors, LVDT, impedance head, and so forth. However it is very important to examine the reliability of the correlated data and the parameters influencing the correlation. Thus, we have conducted experiments on one-dimensional and twodimensional structural systems (beam/plate) with surface bonded PZT sensors and applied the developed procedure to measure and output structural responses in terms of acceleration, displacement, and strain, and so forth.

\section{Experimental Studies on Beams}

Two case studies are carried out; one on an aluminum beam with standard sensors like accelerometer, strain gage, laser sensor, and PZT patches, for demonstrating the usefulness of correlation. In the second case, two sandwich beams are employed (one is healthy and another is with 33\% damage) to show the influence of damage on correlation process.

3.1. Validation for Sensor Correlation Procedure. For this purpose, an aluminum beam of $350 \times 35 \times 3 \mathrm{~mm}^{3}$ has been fabricated. In this beam, near its tip, two PZT patches of different sizes, namely, $20 \times 10 \times 0.5 \mathrm{~mm}^{3}(\mathrm{~S} 1)$ and $15 \times 15 \times 0.5 \mathrm{~mm}^{3}$ (S2), are surface bonded on either side. Three reference sensors are employed; an accelerometer (PCB, model no. 333B32, Sl. no. SN27981 having $102.85 \mathrm{mv} / \mathrm{g}$ sensitivity) is mounted adjacent to one of the PZT patches (top side); a laser point sensor (Micro-Epsilon, model no. OPTONCDT-ILD 1302-50, having $1 \mu \mathrm{m}$ sensitivity and $50 \mathrm{~mm}$ total measuring range with 12 bit resolution) is focused on the tip of the beam; a strain gage is bonded near the fixed end of the beam. In addition to these sensors, a PZT actuator patch is also
TABLE 1: Charge and voltage mode sensitivity of PZT sensor.

\begin{tabular}{lcc}
\hline Sensor type & Sensitivity & $\begin{array}{c}\text { Acceleration } \\
\text { measured }(\mathrm{g})\end{array}$ \\
\hline ICP accelerometer & $102.85 \mathrm{mV} / \mathrm{g}$ & 1.059 \\
PZT sensor (charge mode) & $103.96 \mathrm{pC} / \mathrm{g}$ & 1.040 \\
PZT sensor (voltage mode) & $9.39 \mathrm{mV} / \mathrm{g}$ & 1.077 \\
\hline
\end{tabular}

TABLE 2: Displacement, acceleration, and strain values.

\begin{tabular}{lcccc}
\hline $\begin{array}{l}\text { Parameters } \\
\text { measured }\end{array}$ & Sensitivity & $\begin{array}{l}\text { Output of sensors for different } \\
\text { input forces }\end{array}$ \\
\hline $\begin{array}{l}\text { ICP accelerometer } \\
(\mathrm{g})\end{array}$ & $102.85 \mathrm{mV} / \mathrm{g}$ & $0.4930 \mathrm{~g}$ & $1.124 \mathrm{~g}$ & $1.897 \mathrm{~g}$ \\
Displacement $(\mathrm{mm})$ & - & $0.171 \mathrm{~mm}$ & $0.3496 \mathrm{~mm}$ & $0.698 \mathrm{~mm}$ \\
Strain $(\mu \varepsilon)$ & - & $13.12 \mu \varepsilon$ & $28.63 \mu \varepsilon$ & $51.30 \mu \varepsilon$ \\
PZT-S1 $(\mathrm{g})$ & $103.96 \mathrm{pC} / \mathrm{g}$ & $0.5193 \mathrm{~g}$ & $1.040 \mathrm{~g}$ & $1.99 \mathrm{~g}$ \\
\hline
\end{tabular}

bonded near the root for excitation purpose. Figure 1 shows the geometry of the beam with these mounted sensing and actuating devices and Figure 2 displays the associated experimental setup.

A fixed-free beam configuration is simulated with the help of a mechanical clamp. The PZT actuator patch at the root is used to excite the beam in its fundamental frequency with an acceleration level of $1 \mathrm{~g}$. The disturbance signal is chosen in the sinusoidal form to have a simple harmonic motion of the beam. A signal generator (Scientific Function Generator) is employed to supply the excitation signal of required frequency, which is appropriately strengthened through a high voltage piezo amplifier ( 0 to 150 volt peak to peak) before it is sent to drive the piezoelectric actuator patch (PZT-A1). The response of the beam is simultaneously measured by two PZT patches (PZT-S1, PZT-S2) and the other standard sensing devices. The response signals are acquired using the throughput monitor of LMS SCADAS III and processed with modal analysis software.

The beam is excited in the first mode frequency ( $f=$ $25.96 \mathrm{~Hz}$ ) and the responses from various sensors are measured. The results are presented in Tables 1 to 3 .

In Table 1, the PZT sensor output is given in both charge mode $(\mathrm{pC} / \mathrm{g})$ and voltage mode $(\mathrm{mV} / \mathrm{g})$ and also they are compared with a regular accelerometer output. It can be noticed that the acceleration level observed by the PZT sensor is very much close to the direct measurement. Hence it is evident from this experiment that the PZT patch sensor output can be interpreted as acceleration output directly. It makes the PZT patch act as a smart sensor.

Table 2 gives a comparative picture of other engineering outputs such as displacement and strain, besides the acceleration, which can be obtained from the same patch.

For example, if we substitute the measured displacement value $\left(x=0.698 \times 10^{-3} \mathrm{~m}\right)$ into acceleration $\ddot{x}=-\omega^{2} x$, we get $g_{\text {calibrated }}=-(2 \pi f)^{2} x / 9.8062=1.8937 \mathrm{~g}$ and $g_{\text {measured }}=$ $1.897 \mathrm{~g}$ from accelerometer.

The estimated PZT sensor correlation factor $103.96 \mathrm{pC} / \mathrm{g}$ for sensor S1 gives $1.99 \mathrm{~g}$, which is indeed very close. Therefore, using this procedure, correlation factors for displacement $(\mathrm{pC} / \mathrm{mm})$, strain $(\mathrm{pC} / \mu \varepsilon)$, can be obtained by employing 
TABLE 3: Correlation of two different size PZT sensors.

\begin{tabular}{lcccc}
\hline Sensor type & Sensitivity & Acceleration (g) for different input forces \\
\hline PZT-S1 (g) & $103.96 \mathrm{pC} / \mathrm{g}$ & $0.5193 \mathrm{~g}$ & $1.04 \mathrm{~g}$ & $1.99 \mathrm{~g}$ \\
PZT-S2 (g) & $136.21 \mathrm{pC} / \mathrm{g}$ & $0.5233 \mathrm{~g}$ & $1.06 \mathrm{~g}$ & $1.99 \mathrm{~g}$ \\
\hline
\end{tabular}

already existing dynamic relations. It is worth noticing that for different input forces, the PZT patch has predicted the acceleration level quite consistently along with the accelerometer.

Table 3 presents the accelerations obtained from two patch sensors of different sizes, where one can notice the effect of sensor patch area:

$$
q=\frac{\epsilon A}{t} \varphi
$$

where $q$ is the charge, $A$ is the area of the surface electrode, $t$ is the thickness of the patch, $\epsilon$ is the dielectric permittivity, and $\varphi$ is the sensor potential.

Therefore, by appropriately introducing the surface area $(A)$, the derived " $g$ " levels are seen to be very much comparable at the specified location. This makes the way to interpret the surface bonded or embedded PZT thin films or patches of arbitrary sizes on the composite structure to output engineering parameters for health and load monitoring applications.

\subsection{Influence of Damage on Sensor Correlation. Sensor cor-} relation may be used for two different applications, namely, for structural health and load monitoring; also to detect sensor faultiness. Therefore, it is essential to examine the influence of damage on sensor correlation process. In order to evaluate this, we have fabricated two sandwich beams with and without damage. The sandwich beam is made of two aluminum layers (length $250 \mathrm{~mm}$; thickness $1 \mathrm{~mm}$ each) through adhesive bonding. The debonding is introduced with the help of a thin Teflon patch from the fixed end. Inspection (C-scan) is subsequently done to ensure the presence of damage in the unhealthy beam and no damage in the healthy beam. Experimental test setup for sensor correlation on healthy and unhealthy beams and C-scan picture of the beams are shown in Figure 3.

Experiments are conducted on healthy and unhealthy beams and correlation factors are obtained separately for both the beams and are presented in Tables 4(a) and 4(b). The influence of damage on sensor correlation is then evaluated $(\mathrm{g} / \mathrm{V} ; \mu \varepsilon / \mathrm{V})$. Note that the PZT patch is operated on a voltage mode with the help of a suitable charge to voltage conditioner.

Due to the presence of damage, it is observed that the interpreted engineering parameters (acceleration, strain) from the PZT patch of unhealthy beam with respect to healthy beam have been changed as expected. This is due to the reason that the damage has already reduced the stiffness of the unhealthy beam (the resonant frequency is reduced from 28.5 to $28 \mathrm{~Hz}$ ).

One can notice that these correlation factors depend upon the excitation frequencies and patch locations $(x, y)$. However, once a particular patch is correlated with respect

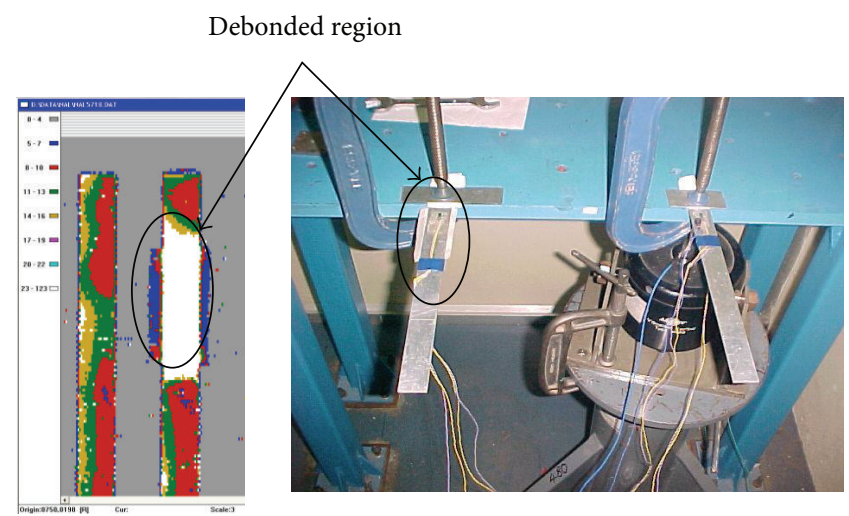

(a) Scanned image

(b) Test setup

FIGURE 3: PZT sensing on healthy and unhealthy beams.

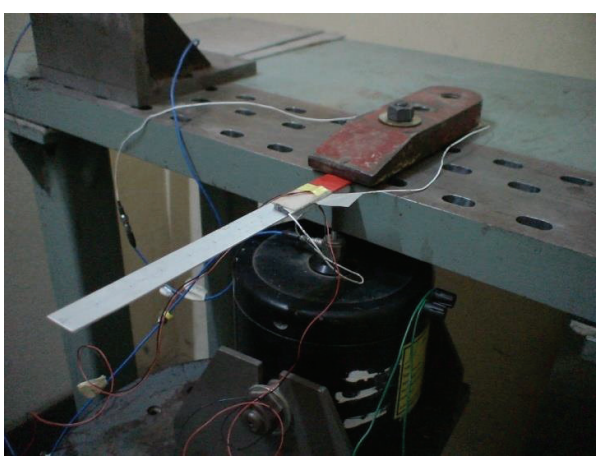

FIGURE 4: Experimental test setup for sensor faultiness study.

to standard sensors, these factors may serve to examine the health of the sensor as well as to monitor the host structure.

In order to study the effect of damage on the correlation factor of the PZT patch sensor, an aluminum beam $200 \times 20 \times$ $1.25 \mathrm{~mm}^{3}$ has been fabricated. Two PZT patches $40 \times 20 \times$ $0.5 \mathrm{~mm}^{3}$ in size are bonded to the specimen in which one PZT patch is perfectly bonded and the other one is partially (50\%) debonded. One accelerometer is also placed near the PZT patch to monitor the response. Experimental test setup for sensor faultiness study is shown in Figure 4.

The beam specimen is excited around critical frequency using shaker and corresponding output response from accelerometer and PZT patches are collected. Subsequently, correlation factors are calculated based on the accelerometer and PZT responses and are presented in Table 5.

Since the sensor is being small in size, its stiffness contribution is very moderate and thus the resonant frequency almost remains same. In contrast, the damage-like delamination in the host structure reduces its bending stiffness significantly causing change in resonant frequency. The presence of damage in the host structure shifts the response sensitivity of the sensor towards resonant condition. On the other hand, any damage in the sensor reduces its output. It is therefore understood that by correlating the sensor output a preliminary examination can be made to identify the sensor faultiness in the SHM system periodically. The deviation in 
TABle 4: (a) Correlation factors (CF) for healthy beam. (b) Correlation factors (CF) for unhealthy beam.

(a)

\begin{tabular}{lccccc}
\hline Frequency $(\mathrm{Hz})$ & Accelerometer response $(\mathrm{g})$ & Measured strain $(\mu \varepsilon)$ & PZT response $(\mathrm{V})$ & Acceleration CF $(\mathrm{g} / \mathrm{V})$ & Strain CF $(\mu \varepsilon / \mathrm{V})$ \\
\hline 27.5 & 0.0069 & 1.1 & 1.027 & 0.0067 & 1.07 \\
28.0 & 0.0117 & 2.1 & 1.836 & 0.0064 & 1.14 \\
28.5 & 0.0428 & 7.4 & 5.930 & 0.0072 & 1.25 \\
29.0 & 0.0176 & 3.1 & 2.900 & 0.0061 & 1.07 \\
\hline \multicolumn{7}{c}{ Average } & & 0.0066 & 1.132 \\
\hline
\end{tabular}

(b)

\begin{tabular}{lccccc}
\hline Frequency $(\mathrm{Hz})$ & Accelerometer response $(\mathrm{g})$ & Measured strain $(\mu \varepsilon)$ & PZT response $(\mathrm{V})$ & Acceleration CF $(\mathrm{g} / \mathrm{V})$ & $\mathrm{Strain}$ CF $(\mu \varepsilon / \mathrm{V})$ \\
\hline 27.5 & 0.031 & 4.7 & 2.61 & 0.0119 & 1.80 \\
28.0 & 0.037 & 5.9 & 3.29 & 0.0112 & 1.79 \\
28.5 & 0.028 & 4.6 & 2.70 & 0.0104 & 1.70 \\
29.0 & 0.018 & 3.2 & 1.97 & 0.0093 & 1.62 \\
\hline \multicolumn{7}{c}{ Average } \\
\hline
\end{tabular}

TABLE 5: Accelerometer and PZT patch (healthy and damaged) response.

\begin{tabular}{|c|c|c|c|c|c|}
\hline Frequency $(\mathrm{Hz})$ & $\begin{array}{l}\text { Accelerometer response } \\
(\mathrm{g})\end{array}$ & $\begin{array}{l}\text { Perfectly bonded PZT } \\
\text { response }(\mathrm{V})\end{array}$ & $\begin{array}{l}\text { Debonded PZT } \\
\text { response }(\mathrm{V})\end{array}$ & $\begin{array}{c}\text { CF }(g / V) \text { perfectly } \\
\text { bonded PZT }\end{array}$ & $\begin{array}{c}\text { CF (g/V) debonded } \\
\text { PZT } \\
\end{array}$ \\
\hline 20 & 0.048 & 0.78 & 0.26 & 0.061 & 0.184 \\
\hline 20.5 & 0.066 & 1.10 & 0.36 & 0.060 & 0.183 \\
\hline 21 & 0.093 & 1.60 & 0.56 & 0.058 & 0.166 \\
\hline 21.5 & 0.176 & 3.00 & 0.92 & 0.058 & 0.191 \\
\hline 22 & 0.600 & 10.8 & 3.28 & 0.055 & 0.182 \\
\hline 22.5 & 0.230 & 4.30 & 1.36 & 0.053 & 0.169 \\
\hline 23 & 0.110 & 2.40 & 0.72 & 0.045 & 0.152 \\
\hline 23.5 & 0.070 & 1.60 & 0.55 & 0.043 & 0.127 \\
\hline 24 & 0.050 & 1.30 & 0.40 & 0.038 & 0.125 \\
\hline \multicolumn{4}{|c|}{ Average } & 0.052 & 0.164 \\
\hline
\end{tabular}

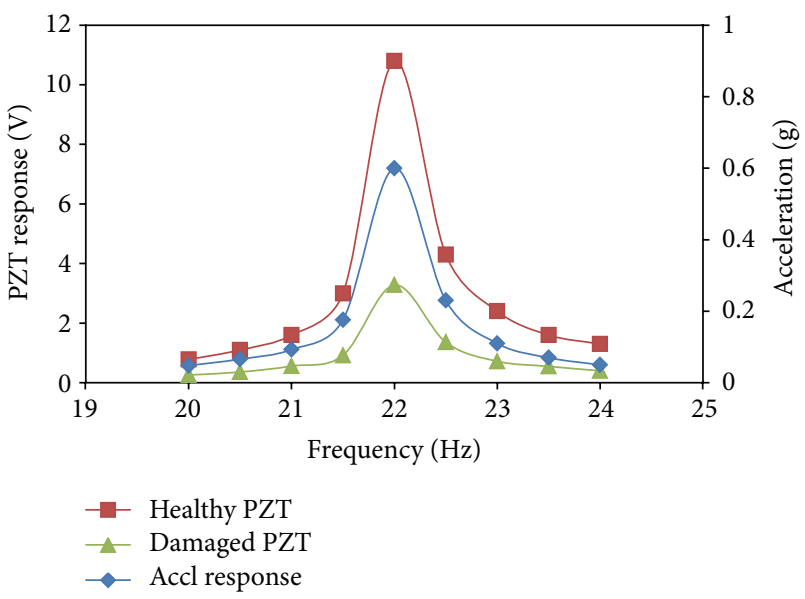

FIGURE 5: Variation in PZT response-healthy and damaged.

averaged correlation factor is noticed to be around $215 \%$ for damage in sensor and it is $62 \%$ in the case of damage in the structure with respect to healthy system. The variation in the PZT responses of undamaged and damaged sensors along with accelerometer response is plotted in Figure 5.
The experiments were conducted on specimens with and without damages at room temperature conditions. The electrothermal coupling is assumed to be very marginal in this environmental condition. Since a known damage is introduced both in the structure as well as PZT patches, it is expected that the stiffness degradation has caused the frequency/amplitude shift in the response.

\section{Experimental Studies on Composite Plate for Load Monitoring}

The developed "sensor correlation" technique has been subsequently implemented on a composite plate structure for load monitoring in terms of dynamic bending moments. Composite test specimens are fabricated using fourteen bidirectional E-glass/epoxy plies of size $400 \times 400 \times 1.5 \mathrm{~mm}^{3}$. The laminate is made of Hexply 914 prepreg tape, with $45 \%$ resin content by weight. The laminate is cured in an autoclave as per manufacture cure cycle and it is then cut into plates of $190 \mathrm{~mm}$ long, $150 \mathrm{~mm}$ wide. A $40 \mathrm{~mm}$ length of the specimen is used for the purpose of clamping. The mechanical properties of bidirectional Hexply 914 laminate are given in Table 6. 


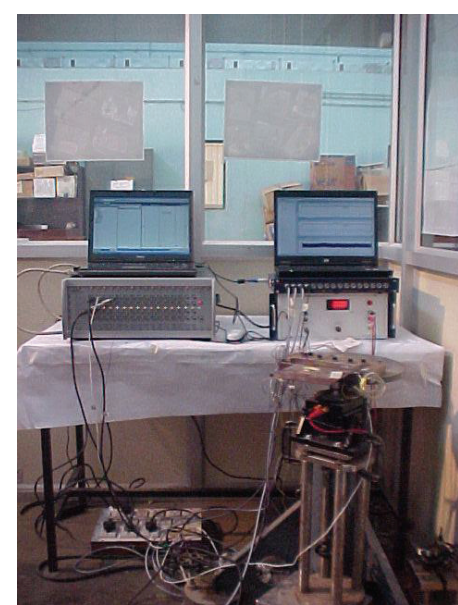

Hardware and software

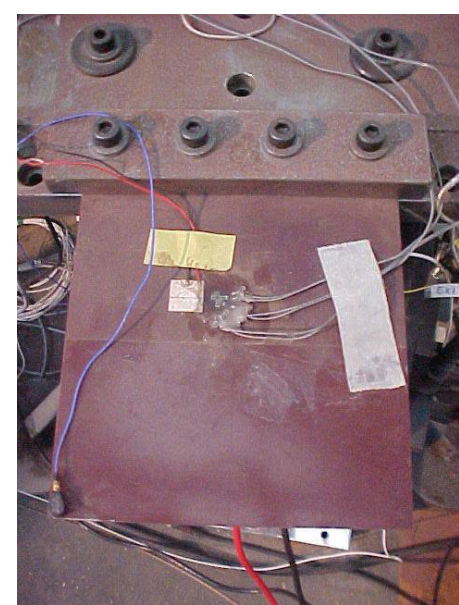

Test specimen clamped to jack

Figure 6: Experimental test setup for vibration monitoring.
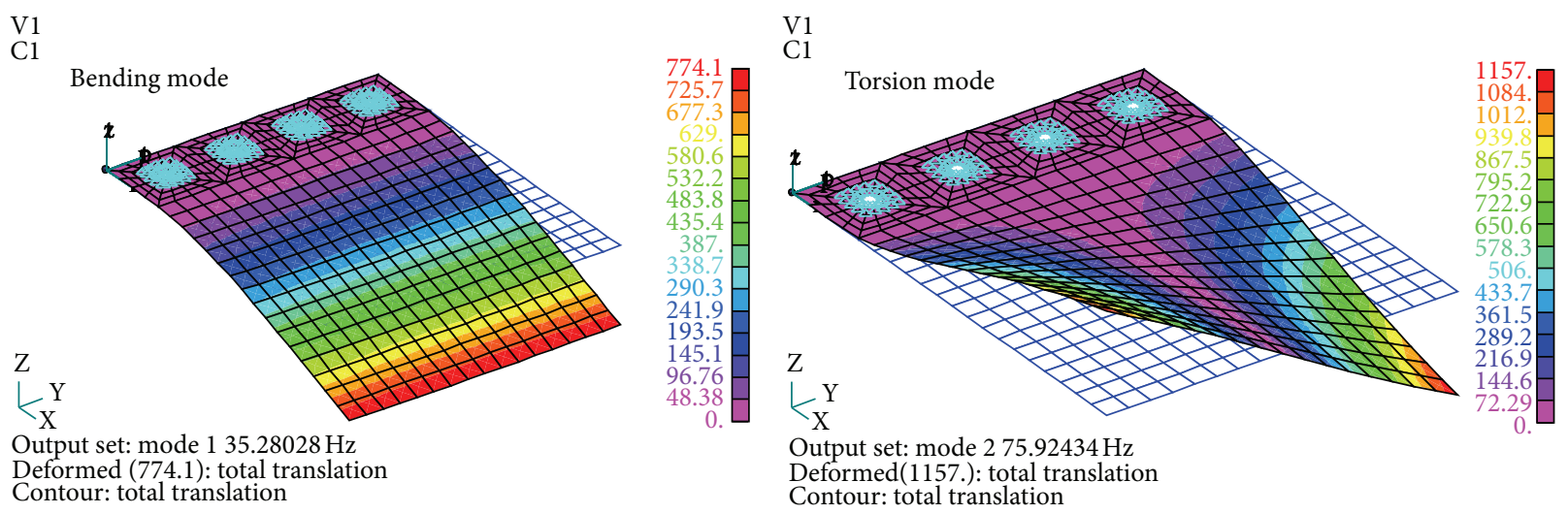

FIgURE 7: Bending and torsion mode shapes of the plate.

TABLE 6: Mechanical properties of Hexply 914 laminate.

\begin{tabular}{lc}
\hline Longitudinal modulus & $25 \mathrm{GPa}$ \\
Transverse modulus & $25 \mathrm{GPa}$ \\
Longitudinal Shear modulus & $5.45 \mathrm{GPa}$ \\
Transverse Shear modulus & $5.45 \mathrm{GPa}$ \\
Poisson's ratio & 0.25 \\
Mass density & $1780 \mathrm{~kg} / \mathrm{m}^{3}$ \\
\hline
\end{tabular}

Three PZT patches are surface bonded to the specimen, in which two are placed on the bottom surface of the plate and one on the top. Out of the two patches in the bottom side, one is used as an actuator. A rosette type reference strain gauge is surface bonded on the top of the specimen for the purpose of strain measurement in normal $(X$ and $Y$ ) and shear $(X Y)$ directions. The details of the strain gage are tabulated in Table 7.

The instrumented structure and experimental setup used for vibration monitoring are presented in Figure 6 . The clamped boundary condition is enforced using a hydraulic jack and with two mild steel plates $\left(40 \times 150 \times 20 \mathrm{~mm}^{3}\right)$ on top
TABLE 7: Strain gauge details.

Foil strain gauge
Type
Gauge length
Resistance
Gauge factor
Thermal output
Lot no

Manufacturer
Rosette

$5 \mathrm{~mm}$

$120.0 \pm 0.3 \% \Omega$

$2.11 \pm 1 \%$

$\pm 2 \mu \varepsilon /{ }^{\circ} \mathrm{C}$

6105-911

Showa measuring instruments, Tokyo, Japan
N32-FA-5-120-23

and bottom of the composite laminate through four M8 bolts. The bolts are tightened to $32 \mathrm{~N}-\mathrm{m}$ using a torque wrench. A vibration generator (Spranktronics, India) is used to excite the laminated plate along with the $\mathrm{PCB}$ force transducer (208C02), which has got $11 \mathrm{mV} / \mathrm{N}$ sensitivity. A PCB accelerometer (353C02), having $100 \mathrm{mV} / \mathrm{g}$ sensitivity, is employed to measure the acceleration. The input force and acceleration are directly acquired in the LMS SCADAS III hardware and processed with LMS Test.Lab software. On the other hand 
the strain is measured in Prosig hardware and processed further using DATS software.

The plate specimen is excited with $10 \%$ burst random signal. The frequency band of interest has been kept as $0-100 \mathrm{~Hz}$, with a frequency resolution of 0.195 (512 time samples). The time domain signals of both force transducer and accelerometer are monitored online. Twenty averages of the time responses have been used to obtain the noise-free response signal by maintaining adequate quality of measurement. Uniform window is applied to both excitation and response signals to have leakage-free data. Programmable antialiasing filters are also used for both excitation and response channels to avoid aliasing errors. Transfer functions (Frequency Response Function (FRF)) are calculated using traditional H1 method between a response signal (acceleration) and a reference signal (force) and are stored. The FRF is then fed into stabilization algorithm to identify the stable modes. The frequencies and modal damping are then calculated for the identified stable modes.

4.1. Modeling of the Experimental Structure. A 2D finite element model is generated in FEMAP to compute the free vibration characteristics of composite plate specimen. The four-node quadrilateral laminated plate elements are used (512 in total) to analyze the plate specimen in NASTRAN. The stacking sequence of $[0 / 90 / 0 / 90 / 0 / 90 / 0 / 90 / 0 / 90 / 0 / 90 / 0 /$ $90]_{\mathrm{T}}$ is used to idealize the fourteen plies laminate configuration. The finite element analysis (FEA) is performed to determine the frequencies and mode shapes of the plate specimen. Figure 7 shows the bending and torsion modes of the specimen, which are considered as critical from the aeroelastic stability point of view (bending-torsion flutter).

The frequency and mode shape comparison between experiment and FEA analysis are presented in Table 8. A good agreement is observed between experiment and finite element analysis results.

In order to monitor the vibration around the vicinity of the targeted frequencies (critical modes), the composite plate is excited using a shaker (near the root). Strains, acceleration, and PZT output are measured by exciting the specimen with a constant input dynamic force of $0.5 \mathrm{~N}$ around the critical frequencies. A frequency band around the resonant condition is selected to verify the consistency in sensor correlation. Therefore, the sensor correlation factor is obtained for resonant and off-resonant frequencies. These values are statistically averaged to get an effective sensor correlation factor. The frequency response analysis is then performed on the finite element model of the laminated plate (reference experimental structure) using MSC/NASTRAN to compute the bending moment around the critical frequencies of bending and torsion modes. The same excitation location is chosen to excite the finite element structural model with a similar force. The experimental damping values are included in the response analysis.

The response from the strain gauge; accelerometer, and PZT patch is measured around the bending mode frequency and is presented in Figure 8. One can notice that their behaviors appear to be almost linear.
TABLE 8: Comparison between experiment and FEA results.

\begin{tabular}{lccc}
\hline \multicolumn{2}{c}{$\begin{array}{c}\text { Experiment } \\
\text { Frequency }(\mathrm{Hz})\end{array}$} & $\begin{array}{c}\text { FEA frequency } \\
(\mathrm{Hz})\end{array}$ & $\begin{array}{c}\text { Mode } \\
\text { description }\end{array}$ \\
\hline 35.38 & 0.45 & 35.28 & Bending \\
75.22 & 0.95 & 75.92 & Torsion \\
\hline
\end{tabular}

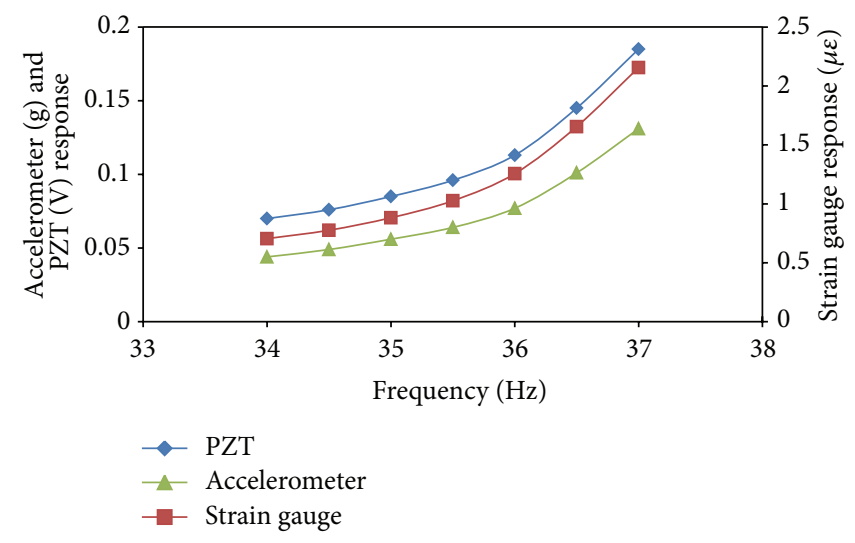

FIGURE 8: Output responses of different sensor.

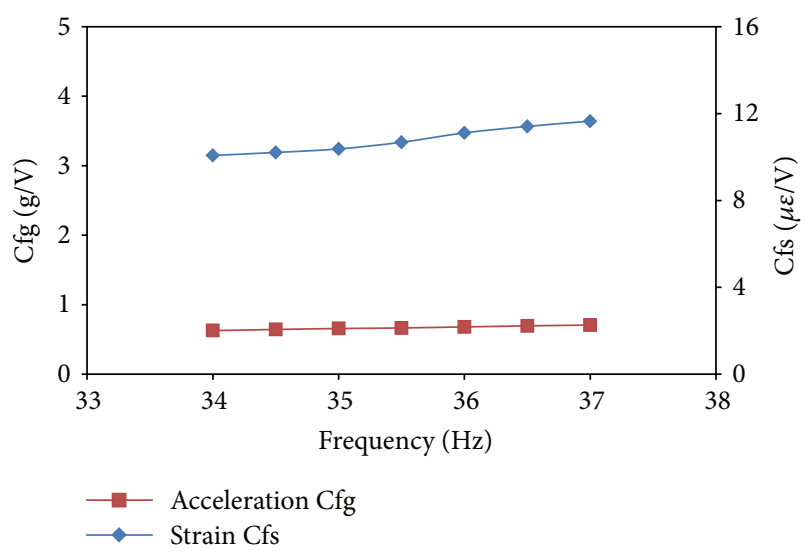

FIGURE 9: Correlation factor of strain and acceleration.

Subsequently, the correlation factors are calculated using the measured response from strain gauge, accelerometer, and PZT patch, which are placed at the same location and the results are plotted in Figure 9. From the figure, one can observe the consistency in calibration factors for both strain and acceleration.

From the PZT patch, both acceleration and strain data are interpreted and verified further with actually measured values. The strain and acceleration, which are measured and calculated using correlation factors are plotted in Figure 10.

Further, the experimentally computed moments are verified with those values, obtained from the finite element analysis for bending and torsion mode and the values are presented in Figure 11.

From the above plot, it is evident that once the correlated PZT output in terms of strains and accelerations is obtained, the stress resultants (bending moments) and critical dynamic loads (maneuvering) in terms of " $g$ " level may be monitored 

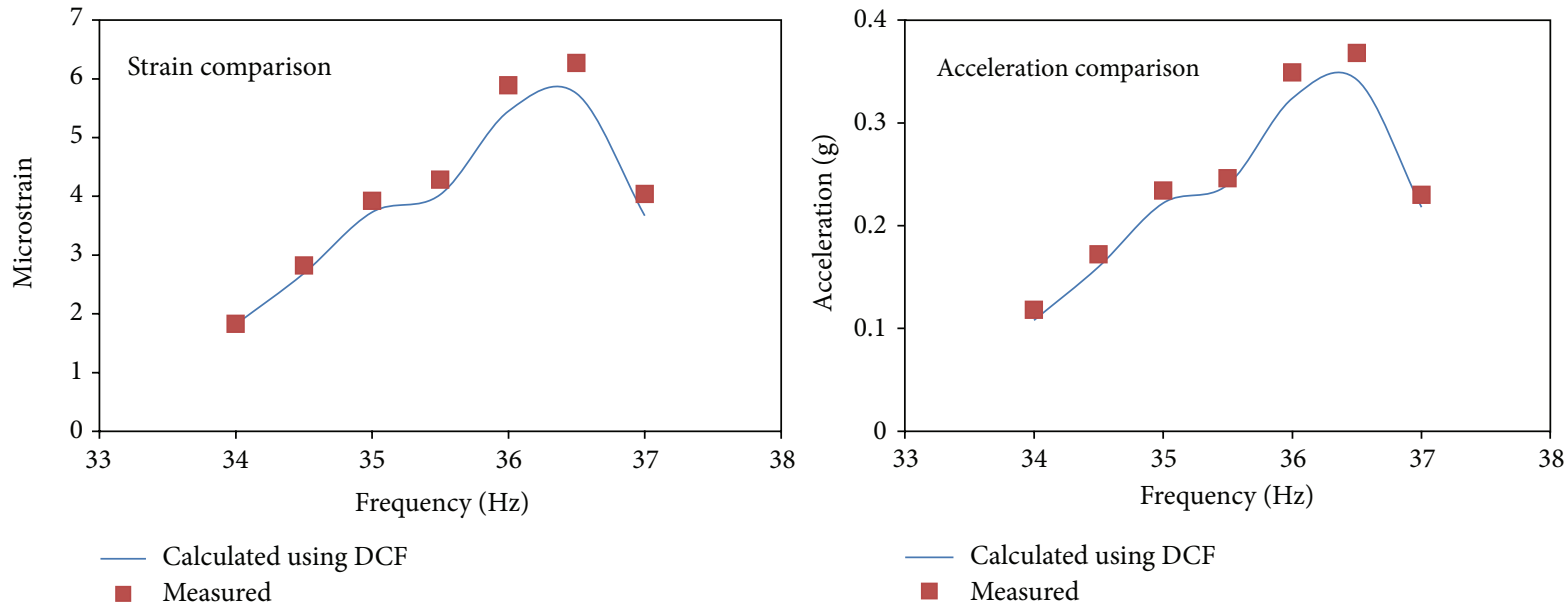

FIGURE 10: Comparison between actual and correlated measurements.
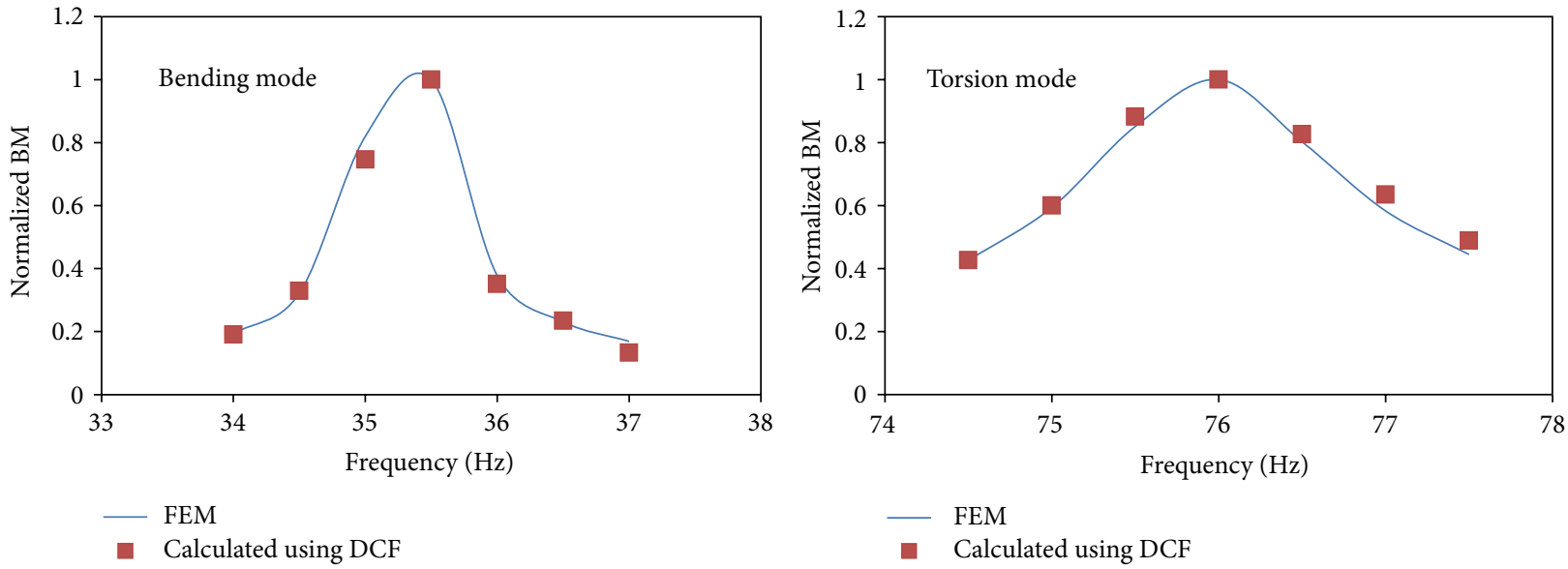

FIGURE 11: Bending moment comparison between FEA and experiment.

at any critical structural location. These stress resultants may be employed in a suitable energy based SHM algorithm to compute damage indices for damage assessment.

\section{Conclusions}

A sensor correlation procedure is developed and verified experimentally for PZT materials using the standard strain gauge, laser displacement and accelerometer. Therefore using standard contact and noncontact sensors such as accelerometers, capacitive sensors, and laser based vibration sensors (velocity or displacement), the embedded or surface bonded PZT patches and piezoelectric composites (MFC, Duract) can be correlated to output engineering data for health and load monitoring applications. The proposed concept can also be applied for calibrating the multifunctional composite structure that will have embedded sensors to have truly smart sensing capabilities. The influence of damage on sensor correlation has revealed that occurrence of damage will change the correlation factor. This may help in taking a decision on detailed inspection (C-Scan/Tomography, etc.).

\section{References}

[1] J. Sirohi and I. Chopra, "Fundamental understanding of piezoelectric strain sensors," Journal of Intelligent Material Systems and Structures, vol. 11, no. 4, pp. 246-257, 2000.

[2] K. Umesh and R. Ganguli, "Shape and vibration control of a smart composite plate with matrix cracks," Smart Materials and Structures, vol. 18, no. 2, Article ID 025002, 2009.

[3] J. R. White, D. E. Adams, and K. Jata, "Structural health monitoring of a metallic sandwich panel by the method of virtual forces," Structural Health Monitoring, vol. 8, no. 6, pp. 537-553, 2009.

[4] Z. Su, X. Wang, L. Cheng, L. Yu, and Z. Chen, "On selection of data fusion schemes for structural damage evaluation," Structural Health Monitoring, vol. 8, no. 3, pp. 223-241, 2009.

[5] S. Kumar, N. Roy, and R. Ganguli, "Monitoring low cycle fatigue damage in turbine blade using vibration characteristics," Mechanical Systems and Signal Processing, vol. 21, no. 1, pp. 480501, 2007.

[6] S. Gopalakrishnan, M. Ruzzene, and S. Hanagud, Computational Techniques for Structural Health Monitoring, Springer Series in Reliability Engineering, Springer, Heidelberg, Germany, 1st edition, 2011. 
[7] V. Giurgiutiu, A. Zagrai, and J. J. Bao, "Piezoelectric wafer embedded active sensors for aging aircraft structural health monitoring," Structural Health Monitoring, vol. 1, no. 1, pp. 4161, 2002.

[8] V. Giurgiutiu and A. Zagrai, "Damage detection in thin plates and aerospace structures with the electro-mechanical impedance method," Structural Health Monitoring, vol. 4, no. 2, pp. 99-118, 2005

[9] A. K. Rao, K. Natesan, M. S. Bhat, and R. Ganguli, "Experimental demonstration of $\mathrm{H}_{\infty}$ control based active vibration suppression in composite fin-tip of aircraft using optimally placed piezoelectric patch actuators," Journal of Intelligent Material Systems and Structures, vol. 19, no. 6, pp. 651-669, 2008.

[10] S. Mohanty, A. Chattopadhyay, and P. Peralta, "Adaptive residual useful life estimation of a structural hotspot," Journal of Intelligent Material Systems and Structures, vol. 21, no. 3, pp. 321-335, 2010.

[11] P. M. Prashant and S. N. Jung, "Support vector machine based online composite helicopter rotor blade damage detection system," Journal of Intelligent Material Systems and Structures, vol. 19, no. 10, pp. 1217-1228, 2008.

[12] M. J. Sundaresan, A. Ghoshal, W. N. Martin, and M. J. Schulz, "A continuous sensor to measure acoustic waves in plates," Journal of Intelligent Material Systems and Structures, vol. 12, no. 1, pp. 41-56, 2001.

[13] C. P. Fritzen, G. Mengelkamp, and A. Guemes, "A CFRP plate with piezo-electric actuators and sensors as self-diagnosing intelligent structure," in Proceedings of the International Conference on Noise and Vibration Engineering, pp. 185-191, Leuven, Belgium, September 2002.

[14] A. Deraemaeker and A. Preumont, "Modal filter for vibration based damage detection," in Proceedings of the 2nd European Workshop on Structural Health Monitoring, Forum am Deutschen Museum, pp. 844-851, Munich, Germany, 2004.

[15] B. F. Spencer Jr., M. E. Ruiz-Sandoval, and N. Kurata, "Smart sensing technology: Opportunities and challenges," Structural Control and Health Monitoring, vol. 11, no. 4, pp. 349-368, 2004.

[16] J. M. Nichols, L. Moniz, M. Seaver, S. T. Trickey, and US Naval Research Laboratory, "Use of holder exponents and fibre optic sensing for detecting damage in an experimental plate structure," in Proceeding of the 23rd International Modal Analysis Conference (IMAC '05), no. 197, Orlando, Fla, USA, 2005.

[17] X. Qing, A. Kumar, C. Zhang, I. F. Gonzalez, G. Guo, and F.-K. Chang, "A hybrid piezoelectric/fiber optic diagnostic system for structural health monitoring," Smart Materials and Structures, vol. 14, no. 3, pp. S98-S103, 2005.

[18] P. Castellini, D. P. Willemann, and G. M. Revel, "Application of a laser doppler vibrometry for structural diagnostics on composite panels," in Proceeding of the 23rd International Modal Analysis Conference (IMAC '05), no. 371, Orlando, Fla, USA, 2005.

[19] B. J. Grisso, L. A. Martin, and D. J. Inman, "A wireless active sensing system for impedance-based structural health monitoring," in Proceeding of the 23nd International Modal Analysis Conference (IMAC '05), no. 336, Orlando, Fla, USA, 2005.

[20] J. M. Park, J. W. Kong, D. S. Kim, and D. J. Yoon, "Nondestructive damage detection and interfacial evaluation of singlefibers/epoxy composites using PZT, PVDF and P(VDF-TrFE) copolymer sensors," Composites Science and Technology, vol. 65, no. 2, pp. 241-256, 2005.

[21] B. Bonfiglioli, A. Strauss, G. Pascale, and K. Bergmeister, "Basic study of monitoring on fibre reinforced polymers: theoretical and experimental study," Smart Materials and Structures, vol. 14, no. 3, pp. S12-S23, 2005.

[22] S. Park, J. J. Lee, C. B. Yun, and D. J. Inman, "A built-in active sensing system-based structural health monitoring technique using statistical pattern recognition," Journal of Mechanical Science and Technology, vol. 21, no. 6, pp. 896-902, 2007.

[23] C. White, B. Whittingham, H. C. H. Li, I. Herszberg, and A. P. Mouritz, "Vibration based structural health monitoring of adhesively bonded composite scarf repairs," in Proceeding of the 5th Australasian Congress on Applied Mechanics (ACAM '07), pp. 198-203, Engineers Australia, Brisbane, Australia, 2007.

[24] X. Liu and Z. Jiang, "Design of a PZT patch for measuring longitudinal mode impedance in the assessment of truss structure damage," Smart Materials and Structures, vol. 18, no. 12, Article ID 125017, 2009.

[25] Y. Yang, H. Liu, V. G. M. Annamdas, and C. K. Soh, "Monitoring damage propagation using PZT impedance transducers," Smart Materials and Structures, vol. 18, no. 4, Article ID 045003, 2009.

[26] Q. Lei, Y. Shenfang, W. Qiang, S. Yajie, and Y. Weiwei, “Design and experiment of PZT network-based structural health monitoring scanning system," Chinese Journal of Aeronautics, vol. 22, no. 5, pp. 505-512, 2009.

[27] C. N. Sathyanarayana and S. Raja, "Multifunctional structure calibration by single measurement using hybrid approach for response monitoring," in Proceeding of the of International Conference on Theoretical, Applied, Computational and Experimental Mechanics, paper ICTACEM -2010/316, Indian Institute of Technology, Kharagpur, India, December 2010.

[28] V. G. M. Annamdas and C. K. Soh, "Application of electromechanical impedance technique for engineering structures: review and future issues," Journal of Intelligent Material Systems and Structures, vol. 21, no. 1, pp. 41-59, 2010.

[29] K. Diamanti and C. Soutis, "Structural health monitoring techniques for aircraft composite structures," Progress in Aerospace Sciences, vol. 46, no. 8, pp. 342-352, 2010. 

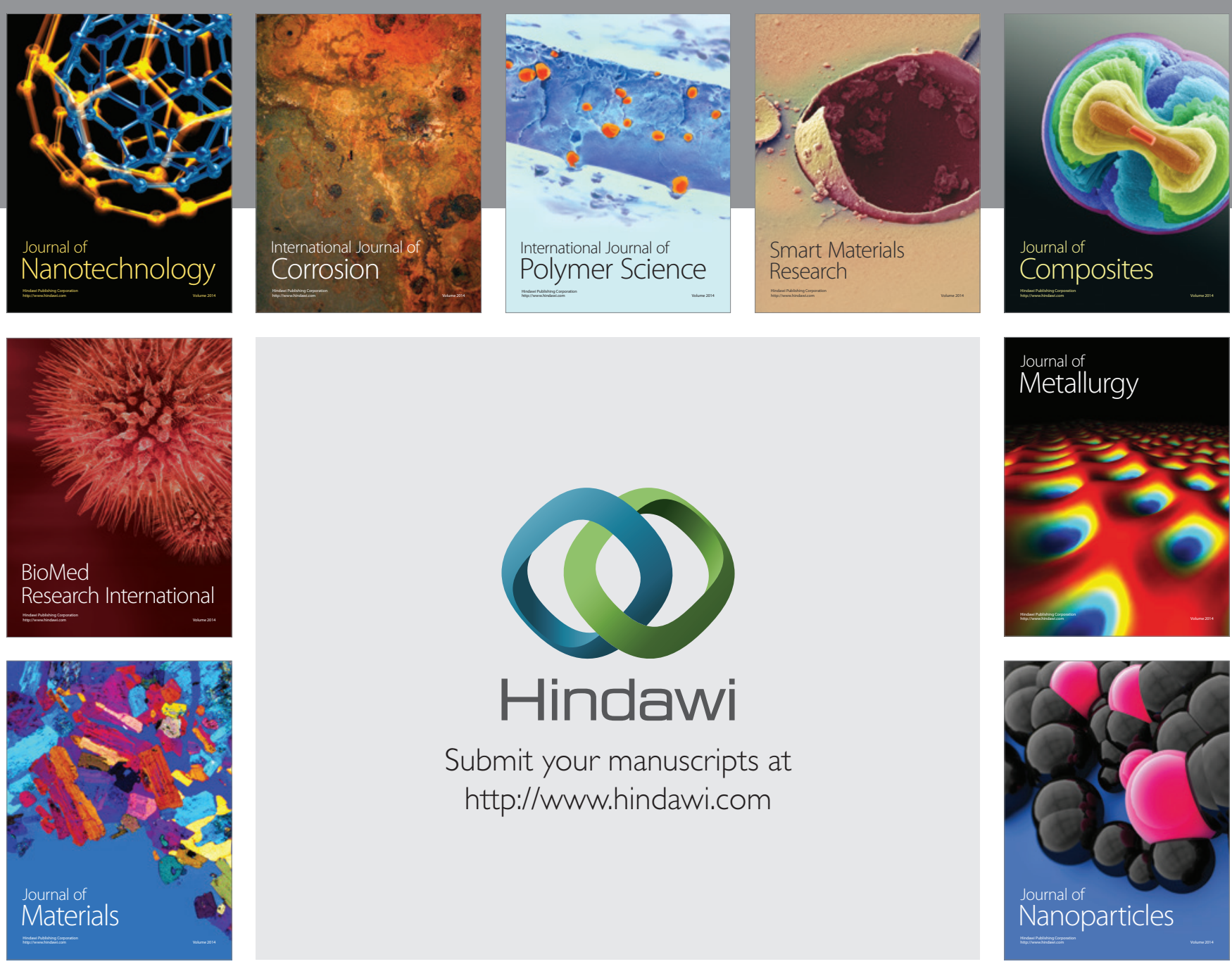

Submit your manuscripts at http://www.hindawi.com
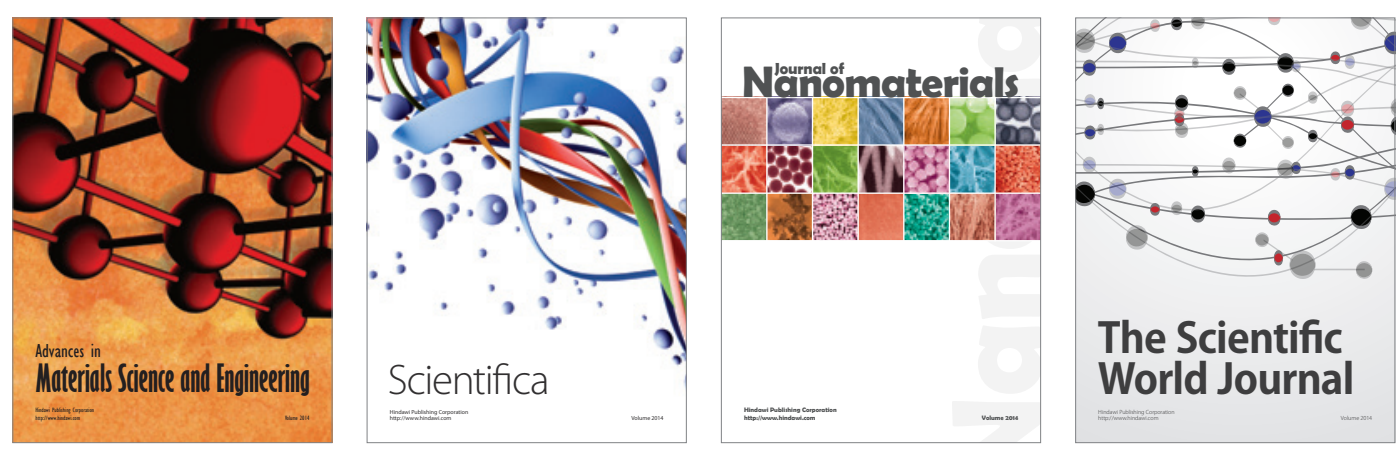

\section{The Scientific World Journal}
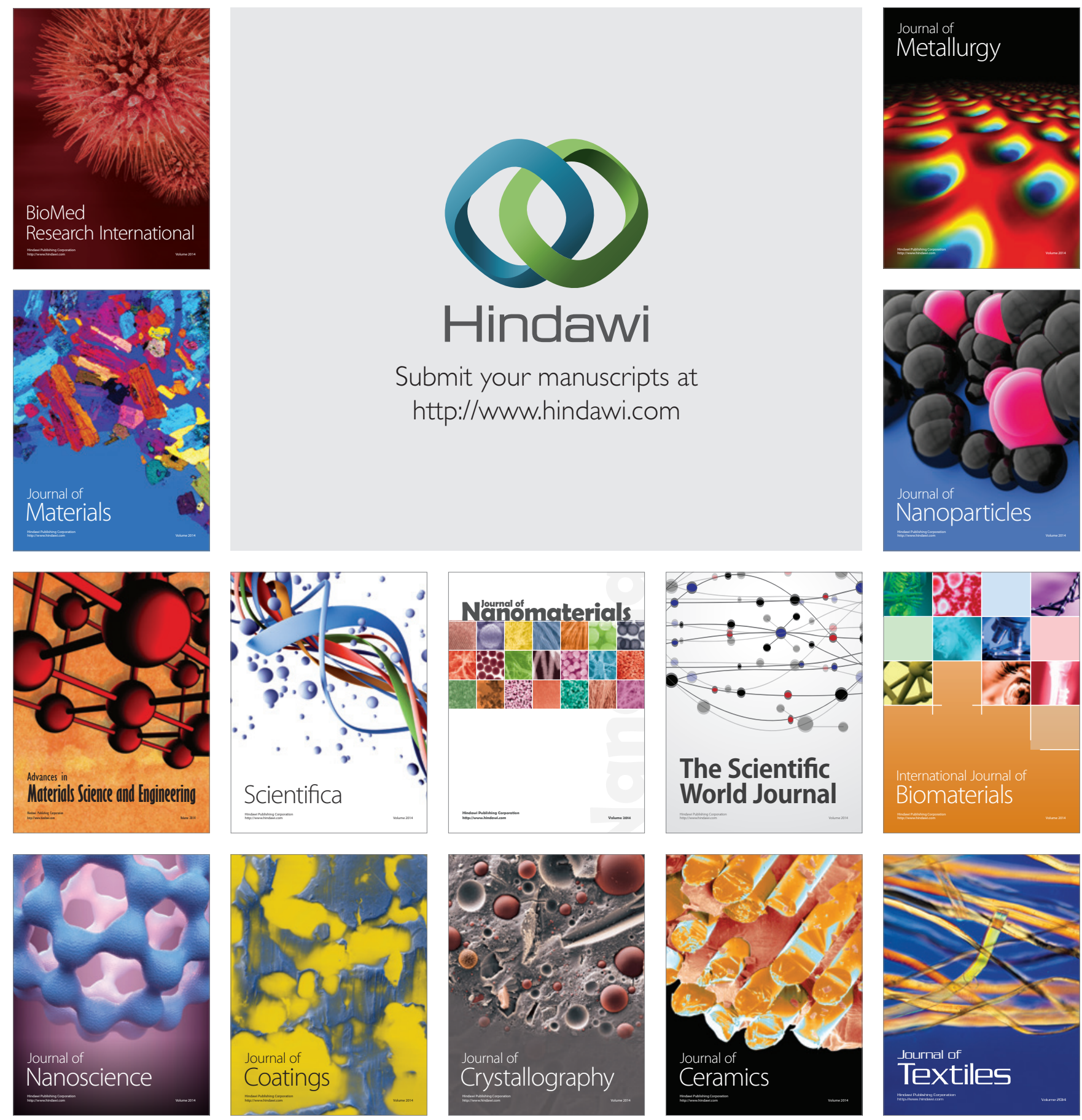